\title{
Crumbling Forests and the Baka: An Anthropological Insight into Forest Conservation in Cameroon's South Eastern Region
}

\author{
Franklin Forzo Titang* \\ Research Graduate, Cultural Anthropology \& Development Studies, Faculty of Social Sciences, KU Leuven, \\ Belgium \\ *Corresponding Author: Franklin Forzo Titang, Research Graduate, Cultural Anthropology \& \\ Development Studies, Faculty of Social Sciences, KU Leuven, Belgium
}

\begin{abstract}
Conservation reserves and parks established in Cameroon's South Eastern Region has precipitated significant socioeconomic consequences on local indigenous Baka communities, offering them little or no opportunities to negotiate free space and access, thereby posing a threat to guaranteeing local livelihoods. This paper discusses the wavering dynamics and epistemologies of fortress conservation, as reflective on local indigenous communities in Cameroon, with case study the Baka Pygmies. Applying an anthropological lens to the analysis, the papers' central theme focuses on deconstructing the polemics and ambiguities surrounding conservation and the promotion of sustainable livelihoods. The paper succinctly discusses how conservation has reshaped and restricted social interactions amongst the Baka and their immediate surroundings, as well as portraying implicitly the human ecological relationships generated as a result. I question further the theoretical assumptions underlying conservation policies and or paradigms, following a brief historical review of conservation subjectivities encountered by the local indigenous Baka community in and around locally established conservation areas. Being an exegetical rather than a reconstructive analysis, this paper contributes to ongoing discourses on environmental sustainability by suggesting pertinent implications for Anthropology and its emerging role in establishing a common ground of understanding as a novel ethnographic approach to political development in Africa.
\end{abstract}

Keywords: Fortress Conservation, Cameroon, Baka, Sustainable Livelihoods, Environmental Sustainability

\section{INTRODUCTION}

Over the last decade or so, international conventions on climate change, biodiversity have increasingly dominated the international sustainable development agenda. The global policy shift from the Millennium Development Goals (MDG's) at the end of its tenure in 2015 to the adoption of Sustainable Development Goals (as set by the United Nations following consultations on the Post 2015 Development Agenda), clearly established the need for renewed thinking and alternative paradigms in development cooperation to ensure environmental stability and sustainability. The term "green conditionality" has become the driving force for so called "green institutions" towards ensuring sustainable development, as states rush to meet up with environmental protection measures. However, the spectacle of conservation to guarantee human well being and safe guard natural habitats relied on the premise that man and his environment are one in a whole. The fundamental thinking underlying the discourse propagated by international environment agencies and organizations is axed on the argument that it is in man's own interest to diminish and or placate actions that seemingly contribute towards global environmental deterioration ${ }^{1}$. Regrettably, this had been impaired by the controversies surrounding discourses on environmental sustainability, the major point of contention being the destructive influence of man's actions on the ecosystem. As exhaustively argued in The Lie of the Land (Leach \& Mearns, 1996), the foundations of science and policy discourse regarding environmental sustainability and protection has operationalized environmental sustainability actions as "received wisdom", justifying the need for the West and environmental conservation agencies to take concerted actions to save the planet from man's destructive influence.

\footnotetext{
${ }^{1}$ McAfee, K. (1999). Selling Nature to save it? Biodiversity and Green Developmentalism, Environment and Planning D: Society and Space, Vo lu me 17, p. 133.
} 
In the same vein, this stance is corroborated further by ascertaining the role of scientists and local policy makers in the South, in creating a furry of underrated and unfounded assumptions on environmental sustainability, which victimizes local people's livelihoods and chastises them as obstinate perpetrators of environmental degradation. It is thus unsurprising that the nature/culture debate has always constituted an important binary in the construction of anthropological knowledge and discourse about culture, environment and sustainable development. Recently, the nature-culture debate has seemingly shifted angles towards deliberate attempts of development agencies and environmental corporations to succinctly "demarcate" this nature -culture boundaries or relationships as a measure towards safeguarding the environment and natural habitats; hence conservation. The reclassification of nature and habitats into reserves and or parks for environmental sustainability motives, has received tons of criticism as development theorists argue that it indirectly reinforces western influence and negatively affects the livelihoods of the local people whose natural living habitat have been targeted as conservation reserves. Central to the debate put forth by global environmentalist agencies is the assertion that the problem of environmental degradation and the strategies embarked upon is a sustainable measure to curb the destructive human influence on the environment (Salzman \& Atwood, 1996). In cognizance of this position, development critics through the medium of novel research efforts, have generated salient questions pertaining to the global sustainable development efforts; particularly with key reflections on the deficiency of policy makers and conservation agencies to acknowledge the engagement of local people in environmental consultation processes, as well as in the rational management and exploitation of forest wealth. Besides, this scenario has further been exacerbated by the growing altercations and antagonisms between different conservation ideologies on the one hand, and the guarantee of sustainable livelihoods for the local population on the other. In as much as conservation ambitions underscore the safeguarding of forest and fauna resources, the complacency and incompatibility of this environmental discourse with local people's realities is excruciatingly problematic. Brockington (2008) clearly buttresses this point when he ascertained that "many environmentalists' goals are not necessarily grounded in specific places or rooted in people's every day realities "2. Consequently, this incompatibility is further attenuated by the peculiar "mismatch" between policy actions initiated by international conservation agencies and national governments, and the daily lives and experiences of local communities, all in a bid to achieve environmental sustainability. Arguably in Doherty \& Doyle (2006), one contends that the ambiguities surrounding conservation discourses, concepts, methodologies and processes on another sphere, tend to corroborate this line of thinking with regards to the contextual disparities, existing between conservation paradigms and the lived experiences of local indigenous communities habiting conservation "allotted" spaces or areas.

The "purported" sustainable management of forest resources as a measure of ensuring environmental sustainability via fortress conservation is continuously receiving much attention and criticisms from development theorists. The "expansionist" tendencies of conservation is paradoxically alluded the term "green imperialism" to denote concerted actions ushered in by international bodies comprising of ecologists, conservation organizations and environmentalists, in a bid to set up "protected areas" in the global South ${ }^{3}$. Brockington (2002) provides a somewhat robust definition of fortress conservation as "an approach that seeks to preserve wildlife and their habitat through forceful exclusion of local people who have traditionally relied on the environment in question for their livelihoods." Conversely, the implementation of such approach to environmental sustainability warrants the forceful displacement and eviction of local people from their dwelling places (usually designated as a protected area for the establishment of national parks, nature reserves etc), with very little or no compensation. This poses a great threat to their livelihoods as they find themselves subjected to the whims and caprices of poverty and misery. This is relatively true of the local indigenous Baka community living in the forest zones of Cameroon's South Eastern Region, expostulated by the fact that the reorganization of customary space through forest concessions, establishment of national parks

\footnotetext{
${ }^{2}$ Brockington, D. (2008). Powerful Environmentalisms: Conservation, Celebrity and Capitalism. SA GE Publications, London, Media, Cu lture \& Society, Vo 1. 30(4): pp. 551 -568

3 See Cassiman, A. Conservation Paradigms and Ecotourism. Lecture Notes on Culture, Ecology \& Development, $26^{\text {th }}$ October, 2017, Leuven.
} 
and protected areas, have neglected these forest residents, gradually subsuming and encroaching on their natural habitat and posing serious challenges of sustainable living for this community. Though not an in depth and or exhaustive analysis, this paper highlights briefly, but succinctly the causal/inherent relationship existing between the socio-economic life and natural habitat of the local indigenous Baka community, to vividly underscore the dire effect of the creation of state parks and nature reserves on the livelihoods of this vulnerable community. Concomitantly, the socio-ecological interactions harnessed between this local indigenous community and their immediate environment have been negatively reshaped and reconstructed.

To this effect therefore, a salient discussion and reflection on the theoretical assumptions underlying conservation approaches Cameroon's South Eastern region is needed as an "open statement" towards ushering in conceptual ambiguities surrounding environmental interventions in this area, and then concluding with an anthropological niche and its potential contribution in creating balance between environmental conservation and sustainable livelihoods.

\subsection{Research Problem}

With the ever increasing demand for sustainable development in the 20th century (the global South most especially), the essentiality of environmental protection and conservation measures necessitated an alteration in sustainable development approaches from an anthropocentric perspective towards a more eco-centric approach as concerns preserving wildlife and nature's resources (de Sadeleer, 1994). This premise dominated concurrent discourses in nature conservation as the argument put forth underscored the issue of "access" to forest resources, which virtually was non -existent to local indigenous communities. We then begin to ponder why, as we are categorically drawn to the fact that the raison d'être of this conundrum, is the subsequent adoption of preventive environmental sustainability measures as evidenced by conservation practices ${ }^{4}$. Nonetheless, the very foundations of protected areas within forest conservation debates have been projected throughout historical discourses. Attempts at conservation at the global sphere were initiated prior to the 1993 Second Convention of London, which brought together key stakeholders to ascertain the need for environmental sustainability efforts in the political hemisphere (Roulet, 2004) . Consequently, it became primordial to elaborate a more conservationist-oriented model or strategy towards the sustainable management of forest areas. Central to this proposition, was the need to physically "fence in" the ecosystem as a measure to rigorously attenuate local or consumer exploitation of these natural resource.

This "contested" justification of environmental protection is clearly acclaimed in Ngima (2015), in which he contends vividly that, and I quote "in Central Africa, hunting reserves emerged to serve as fauna resource reserves and the underlying idea was that the animals be preserved, but access to local community inhabitants was denied"5. Nevertheless, forest management through conservation policies at community levels meant denying local communities their legitimate right to freely exploit this principal source of livelihood, especially with their growing populations. This is exegetically explicative of the local indigenous Baka community in Cameroon's South Eastern region, where the absence of other economic opportunities makes forests the key resource for their survival. In the light of this, one questions how actors and key stakeholders of forest protection achieve sustainable management of forest resources while ensuring the socio-economic wellbeing of the local population? What policy options and possibilities exist for forest management sector in Cameroon? This paper contends that successful conservation actions are seemingly more meaningful and "sustainable" in its truest sense, where there are long term alternative livelihood opportunities and strategies put in place for indigenous communities that depend on these forest resources as a means of survival. Besides, we align our analysis on the premise that local (ecological) knowledge, indigenous rights, and community based or participatory natural resource management adopted in the environment-development discourse is more likely to produce positive results in forest conservation practices as local people are directly implicated in the management process

\footnotetext{
${ }^{4}$ De Sadeleer, N. (1994). De la Protection à la Sauvegarde de la Biodiversité. Ecolog ie et Po lit ique, 9: 25-48.

${ }^{5}$ Ngima, M.G. (2015). Attempts at Decentralization, Forest Management \& Conservation in Southeastern Cameroon, African Study Monographs, Suppl. 51: 143-156.
} 


\section{The Spiral of Conservation in CAMERoon's South EASTERn REgion}

\subsection{Context and Trends}

The early 1990's ushered in a new wave and outlook towards forest conservation actions in Cameroon The progressive elaboration and implementation of the country's forest conservation statutes witnessed the break of dawn following the Rio Earth Summit held in Rio de Janeiro in 1992. The central clause of this statute visibly underscored the intrinsic processes and procedures bestowed upon the state in the preservation of natural resources and the obligation to ensure an eco-friendly environment. Ndameu (2001) draws insight into the ambiguities of the state's efforts at conservation to ascertain the complacency and incompatibility of this statute with the objective participation of the local indigenous forest communities in the process. To this effect he points out that "already at the outset, the application of these texts foreshadowed the contradiction inherent in the process; on the one hand undermining the will to link the local people, the residents of the forests with the process, and on another, introducing restrictions that would make the harmonious application of forest law impossible". Arguably, the biogeography of African landscapes was considered essentially natural and primordial which was sharply juxtaposed with the perception that the nature of man is essentially anthropoid, primitive and undeveloped. Such approach embarked upon by the state is reflected in Brockington (2002) who argued implicitly that the neo-liberalization of African subsistence practices as a result of colonial influences, tended to push colonial masters and local governments to valorize "fortress conservation" as an environmental sustainability approach to limit or curb the destructive influences of local peoples subsistence practices on natural and forest resources. With the elaboration of the MDGs a new pace of environmental awareness was set in Cameroon. The mapping out of forest zones throughout the entire territory became imperative for sustainably managing and safeguarding nature's forest resources, leading squarely to the apparent demarcation of dense forest zones in the South Eastern region of Cameroon. Emphasis was placed on the responsible management and use of natural forest resources in a bid to achieve sustainable development and growth. This culminated into a great need to enhance strategic partnerships between government and international stakeholders, and saw the considerable influence of international conservation agencies taking the lead including World Wildlife Fund for Nature (WWF) and GIZ. The presence of external actors in this process seemingly perturbed environmental interventions and continuously negated the sustainability of conservation policies and interventions. This can be seen in Sodikoff (2009) who established that conservation promotes capitalist relationships and exigencies, maintains power relationships, and "legitimizes" international/national conservation development projects. However, replicated within the confines our analysis, one will likely ascertain that not only did the establishment of nature parks and conservation reserves (such as the Lobéké, Boumba Nek \& Nki etc) in the Moloundou area in Cameroon's South Eastern region prove problematic, it as well defined the dilemma in safeguarding nature, without imminently tramping down on livelihood concerns. It is thus needless to emphasize that the local indigenous Baka community habiting the Moloundou area are seemingly caught in this vicious web, as the establishment of these parks and reserves are posing serious threats and challenges to their mode of life and quest for survival.

\subsection{Conservation Polemics \& Current Challenges for the Baka}

The Baka is a local indigenous pygmy community inhabiting most parts of the forest zone in Cameroon's South Eastern region. For thousands of years, the human ecological relationship prominent amongst the Baka, demonstrated a communal relationship or communion with the forest on which they depended on for their livelihood. With the adoption of Cameroon's long term development vision, "Vision 2035", concessions for the massive exploitation of forest and natural resources for development initiatives have seemingly taken primacy of place, given that the country's forest sector stands as a massive source of Cameroon's export earnings, providing more than one quarter of the total revenue from exports. As earlier discussed, this facilitated the establishment of national parks and conservation areas in the Moloundou area, posing a very serious livelihood challenge for the local indigenous Baka community originally inhabiting the area. It is of prime essence to denote that the Baka for centuries have built their home in this forest area, usually relying on the forest for food, medicine and hunting activities. 


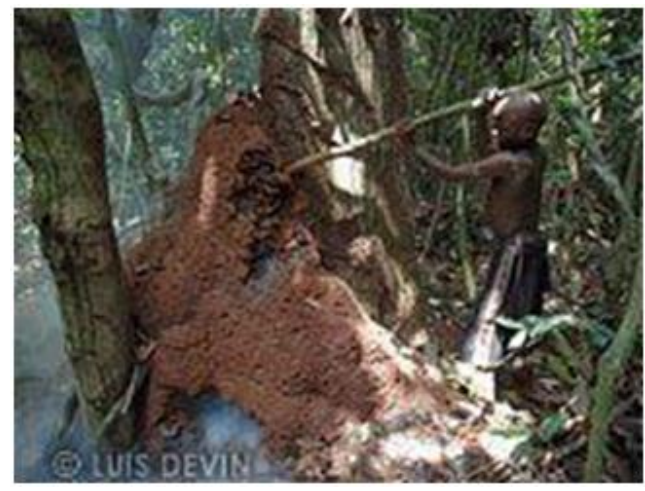

Figure1. Hunting for food by Baka young boy in the forest

Photo credit: Luis Devin (see www.pygmies.org, accessed and retrieved on 25/02/2018)

But with the elaboration of the National Forestry Policy, this seemingly peaceful mode of life is dangerously shifting towards the verge of extinction. This has been further exacerbated by the growing presence of logging companies and other conservation organizations whose "projects" have ultimately pushed this local indigenous community to inhabit the road sides and the very edges of the forest zone, having nothing to look up to but a mere sedentary life. More importantly, the Baka's lack of concessionary rights to land that was initially their home, is being jeopardized as they are unable to freely access, exploit and rummage the forest for food and fruits, conceded to the management auspices of conservation bodies as nature reserves and parks ${ }^{6}$. Needless to lay emphasis on the impact of this process on the way of life of the Baka indigenous community, but one can contend that the alteration of the human ecological relationship previously enjoyed by these people and their original habitat, has comprehensively forestalled their development, making it wholly arduous for them to adapt to changing discourses on environmental sustainability and "preservation".

As Bahuchet (1993) asserts, the Baka considered "the installation of national parks and reserves in their natural habitat as an interference of their livelihood". Irrespective of government's efforts in collaboration with international conservation agencies (such as WWF) and projects to adequately seek solutions to this predicament, the journey still proves perilous for the local indigenous Baka community. As cited previously, the ever increasing presence of logging companies in this forest area as well continues to account for the massive dissipation of forest biodiversity for capitalist gains and profit maximization ventures. Such ambiguities in nature conservation raises questions on access to resources and inherently questions who benefits from the process. In Power and Visibility, Escobar (1988) questions the benefits of conservation (perceived as a capitalist venture) to local communities as seemingly they remain poor and are forced into misery. To this effect, he argues invariably that it is the quest for sustainable development that has brought poor people into a complex web of capitalist and or conservation exigencies, putting them at a disadvantage, through the series of discourses and programs "created" by conservation agencies a nd policy makers to deal with the reality ${ }^{7}$

Poppe (2012) further corroborates the livelihood dilemma of local population as a result of conservation practices by questioning and discussing the relationship between conservation and social/communal relationships. The ambiguities raised in her account reflects the neo-colonization of natural resources, the environment and the nature which vehemently destabilized the communal relationships that previously existed between the so called "rangers" and the entire community. To this account she posits that Rangers being insiders or belonging to these communities are seen as traitors and untrustworthy because they report environmental offences to foresters against their residents. Though not entirely reflective of the Baka, the introduction of fortress conservation schemes in the Eastern region of Cameroon, created landmark conflicts between these indigenous people and other local communities (with whom they previously lived in solidarity with) within the area given that the need to ensure survival, saw the Baka forcibly encroaching onto the lands of these

\footnotetext{
${ }^{6}$ Indigenous Peoples and Protected Areas in Africa: From Principles to Practice, Forest Peoples Programme, 2003, pp. 35-39. Availab le at: http://www.forestpeoples.org/documents/africa/foreword_and_intro_eng.pdf

${ }^{7}$ Escobar, A. (1998). Power and Visibility: Development and the Invention and Management of the Third World . Cultural Anthropology 3(4): pp. 428-443
} 
other communities in search of food and medicine. It is thus not remarkable that the local indigenous Baka community encounter serious prejudice from other neighbouring "Bantu" communities, inhabiting along the edges of the roads and parks as well.

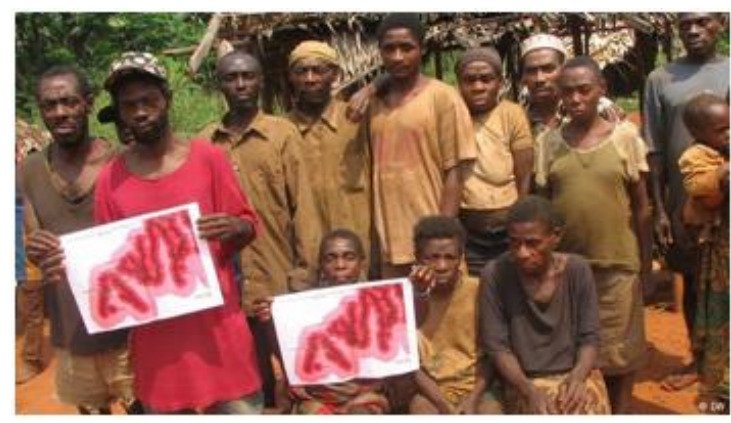

Figure2. Baka pygmies with maps of cut out areas

Photo Credit: Ngala Killiam Chimtom (Accessed on 26/02/2018 and retrieved from http://www.dw.com/en/ ancient-baka-culture-in-cameroon-under-threat/a-16088853)

The alienation of local indigenous people from their once natural habitat and the controversial actions of major stakeholders under the guise of conservation projects severely severed the very foundations of the Baka communal life and social relationships. Fairhead et al (2012) analyzed the dynamic interrelationships existing between the major stakeholders involved in sustainable development efforts, ranging from environmental conservation agencies, NGOs and national/state agencies, foreign logging companies, asserting that "green grabbing" for environmental concerns invariably alienates local people from acquiring and maintaining sustainable livelihoods. Thus, is it credible and justifiable to purport that conservation breeds capitalist tendencies and drives the wheels of profit maximization for external actors in conjunction with national policy makers, at the peril of local indigenous communities?

As previously argued, the ethical influence or force lurking within the confines of a meanderingly constructed environmental sustainability agenda, seemingly endorses and sustains land and natural resource concessions for use as "green fuel plantations, biodiversity offset capital and carbon

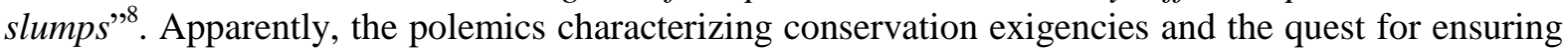
environmental sustainability for development, translates into the concurrent debate of ensuring sustainable livelihoods for local indigenous people while advancing the environmental sustainability agenda. The ontologies and binaries revolving around the human-ecological relationships appear problematic as exemplified by the conservation exigencies be felled on the Baka community in the South Eastern Region of Cameroon. Can we rightly contend that at the forefront of ecological concerns is the need to promote an "alien" sustainable development agenda that may not necessarily reflect the realities of communities believed to be perpetrators of environmental degradation, by simple virtue of their natural and subsistence mode of life?

Regardless of this, it is primordial to underscore that $t$ he pivotal relationship between the continuous survival of a people, its root culture and the environment affiliated to them, constructs considerable opportunities for conservation efforts. This will imply that global goals enacted to guarantee biodiversity will be attained through the creation of an enabling environment that will provide the socio-political platform for local indigenous communities such as the Baka to sustainably manage their own lands. This "people oriented" approach to forest conservation underscored therefore the main tenets put forth by the "new conservation paradigm" . Based on this backdrop, the necessity to reshape perspectives and discourses on environmental conservation becomes of paramount significance as concerted actions of various stakeholders will underscore great value for a novel understanding of human-ecological relationships. Imperatively, a social consultation process involving local indigenous communities like the Baka in Cameroon's South Eastern region becomes a more relevant pathway for the appropriation of novel and contemporary forest management approaches and or methodologies.

\footnotetext{
${ }^{8}$ Fairhead, J., Leach, M., \& Scoones, I. (2012) Green Grabbing: A New Appropriation of Nature?, The Journal of Peasant Studies, Volu me 39:2, pp. 237-261
} 


\section{CONCLUSION}

\subsection{Towards New Paradigms: An Anthropological Approach}

In as much as conservation initiatives ascertain global efforts at ensuring environmental sustainability, global rhetoric on the usage and reparation of ecosystems and the burgeoning market economics, are the driving forces behind the emergence of a contemporary political economy of sustainable livelihoods and land within the global geopolitical landscape. The existence of recent politicoeconomic processes, key stakeholders and structures of resistance, are proof of the contemporary dimensions of discursive framings within the forest conservation approach. The central objective of this paper was to discuss the wavering dynamics and epistemologies of fortress conservation, as reflective on the Baka community in the South Eastern region of Cameroon, so as to deconstruct the polemics and ambiguities surrounding conservation and sustainable livelihoods. Succinctly, we attempted to briefly identify the historical trajectories of conservation and the Baka people in Cameroon, so as to establish the human -ecological relationship existing between the Baka and the forests area. Using anthropological analysis and discursive frameworks on conservation, we contend that successful conservation actions are seemingly more meaningful and "sustainable" in its truest sense, where there are long term alternative livelihood opportunities and strategies put in place for indigenous communities that depend on these forest resources as a means of survival. As earlier explained, the correlated dynamics surrounding conservation practices presents diversified ramifications particularly for local indigenous communities. What alternative spaces for change and innovation are available in this current trend to ensure environmental sustainability? Ironically, as discussed in our ana lysis, the establishment and or creation of enclosures and protected areas upheld by some environmental theorists as a succinct contribution to the sustainability of the planet rather seem to spawn more profits for "capitalist" businesses and multinationals. In this regard, determining a win-win relationship is incumbent on stakeholders. It will depend on an entire shift from previous dominating discourses on environmental sustainability, to generating new paradigms and rethinking new approaches that will serve as a basis for the equitable policy making and the much acclaimed green growth.

To this effect, the implications for Anthropology and its emerging role in establishing a common ground of understanding as a novel ethnographic approach to sustainable development on the one hand is inherently primordial. One is thus enticed to question substantially the modes of local participation and how these can be safeguarded in a decision making process subjected to conditions of integrity, answerability and popular consent. The rethinking of new conservation paradigms such as community conservation schemes in the environmental sustainability discourse stands to establish a novel approach to development, as the beneficial trend is to underscore a combination of scientific knowledge and indigenous knowledge on human-ecological relationships, so as to ascertain a holistic strategy for promoting green objectives.

Regardless of this consideration, it will be pivotal to implicitly question the centrality of social justice within the conservation discourse. Set aside, this will mean drawing nature off the claws of capitalist orientations, strengthening indigenous and or local discernment of human ecological relationships and the deep seated exigencies and tenets of the nature debate earlier discussed. Anthropologists could be keen to dissect the dynamics of development interventions and policy as a first step for creating balance between environmental conservation and sustainable livelihoods on the other. This requires recasting the debate, asking what role or potential contribution could be earmarked for Anthropologists, and will alternatively foster a complete rethinking of policy as well as scholarly objectives on development and environment concerns. Possible choices must emerge, entrenched in analogous, complementary and ardent understandings of the socio-cultural realities of landscapes, human-ecology interconnections, as an effervescent response to the turbulent bionomics and politics of the real world. And who better placed to provide such than anthropologists themselves.

\section{REFERENCES}

[1] Bahuchet, S. (1993). La Rencontre des Agriculteurs: Les Pygmées Parmi les Peuples d'Afrique Centrale. Peeters, Paris.

[2] Brockington, D. (2002). Fortress Conservation: The Preservation of the Mkomazi Game Reserve, Tanzania. Indiana University Press, Indiana. 
[3] Brockington, D. (2008). Powerful Environmentalisms: Conservation, Celebrity and Capitalism. SAGE Publications, London. Media, Culture \& Society Vol. 30(4): 551568

[4] Cassiman, A. Conservation Paradigms and Ecotourism. Lecture Notes on Culture, Ecology \& Development, $26^{\text {th }}$ October 2017, Belgium, KU Leuven.

[5] De Sadeleer, N. (1994). De la Protection à la Sauvegarde de la Biodiversité. Ecologie et Politique, 9: 2548 .

[6] Doherty, B. \& Doyle, T. (2006) 'Beyond Borders: Transnational Politics, Social Movements and Modern Environmentalisms’, Environmental Politics 15(5): 697-712.

[7] Escobar, A. (1998). Whose knowledge, Whose mature? Biodiversity, Conservation, and the Political Ecology of Social Movement. Journal of Political Ecology, 5: 53-82.

[8] Escobar, A. (1998). Power and Visibility: Development and the Invention and Management of the Third World. Cultural Anthropology 3(4): pp. 428-443

[9] Fairhead, J., Leach, M., \& Scoones, I. (2012) Green Grabbing: A New Appropriation of Nature? The Journal of Peasant Studies, Volume 39:2, pp. 237-261

[10] Freilich, M. (1967), Ecology and Culture: Environmental Determinism and the Ecological Approach in Anthropology, Anthropological Quarterly, Vol. 40, No. 1, pp. 26-43

[11] Government of Cameroon. 1994. Law No.94-01 of January 1994 to Lay Down Forestry, Wildlife and Fisheries Regulations. Government of Cameroon, Yaoundé. — 1995. Decree No 95-531-PM of 23 August 1995 Laying Down the Procedure for Implementing the Forests System. Government of Cameroon, Yaoundé.

[12] Indigenous Peoples and Protected Areas in Africa: From Principles to Practice, Forest Peoples Programme, 2003, pp. 35-39. Available http://www.forestpeoples.org/documents/africa/foreword_and_ intro_eng.pdf

[13] Lohmann, L. (2009). Neo-liberalism and the Calculable World: The Rise of Carbon Trading. In: Bohm, S. and S. Dabhi (eds) Upsetting the Offset: The Political Economy of Carbon Markets, London: Mayfly Books, pp. 25-40

[14] McAfee, K. (1999). Selling Nature to save it? Biodiversity and Green Developmentalism, Environment and Planning D: Society and Space, Volume 17, p.133.

[15] Neba, E. \& Fonjong, L. N. (2002), Actors, Options and the Challenges of Forest Management in Anglophone Cameroon, Kluwer Academic Publishers, Netherlands,. GeoJournal 57: 95-111, 2002.

[16] Ndameu, B. (2001). Zones protégées et populations autochtones : Antinomie des logiques de conservation et de survie chez les Baka de la région de Moloundou (sud-est Cameroun), In (J.Nelson \& L. Hossack, eds.) Les Peuples Autochtones et les Aires Protégées en Afrique : Du Principe à la Pratique, pp. $217-242$. Forest People Program, Moreton.

[17] Ngima, M.G. (2015). Attempts at Decentralization, Forest Management \& Conservation in Southeastern Cameroon, African Study Monographs, Suppl. 51: 143-156.

[18] Njiei, A. F. \& Asongu, N. A. (2015) Development Challenges Amongst The Baka People Of The Eastern Region Of Cameroon: An Anthropological Perspective, International Journal of Innovation and Applied Studies Vol. 12 No. 2, pp. 440-446

[19] Poppe, J. (2012) Conservation's Ambiguities: Rangers on the Periphery of the W Park, Burkina Faso, Journal of Conservation and Society 10(4): 330--343

[20] Roulet, P.A. (2004a). Potentialités et Limites du Modèle de Zones de Chasse Communautaires en Afrique Centrale. La Chasse Sportive Comme Outil de Gestion de la Faune Sauvage et de Développement Local? Fondation Internationale pour a Sauvegarde de la Faune, Bangui.

[21] Salzman, P.C. \&. Attwood, D.C. (1996). Ecological Anthropology, In (B. Alan \& L. Spencer, Eds.) Encyclopedia of Social and Cultural Anthropology, pp. 256-261. Routledge, London.

[22] Sodikoff, G. (2009), The Low-Wage Conservationist: Biodiversity and Perversities of Value in Madagascar, American Anthropologist • Vol. 111, No. 4 • December 2009

Citation: Franklin Forzo Titang. "Crumbling Forests and the Baka: An Anthropological Insight into Forest Conservation in Cameroon's South Eastern Region" International Journal of Research in Sociology and Anthropology (IJRSA), vol 5, no. 1, 2019, pp. 64-71. doi:http://dx.doi.org/ 10.20431/2454-8677.0501007.

Copyright: (C) 2019 Authors. This is an open-access article distributed under the terms of the Creative Commons Attribution License, which permits unrestricted use, distribution, and reproduction in any medium, provided the original author and source are credited. 